Supporting information

\title{
Boosting multiple interfaces by co-doped graphene quantum dots for high efficiency and durability perovskite solar cells
}

Hui Chen, ${ }^{1, \dagger}$ Qiang Luo, ${ }^{2, \dagger}$ Tao Liu, ${ }^{2}$ Meiqian Tai, ${ }^{3}$ Jing Lin,,${ }^{4, *}$ Vignesh Murugadoss, ${ }^{5,6}$ Hong Lin, ${ }^{3}$ Jinshu Wang, ${ }^{1 *}$ Zhanhu Guo, ${ }^{7 *}$ and Ning Wang, ${ }^{1,2, *}$

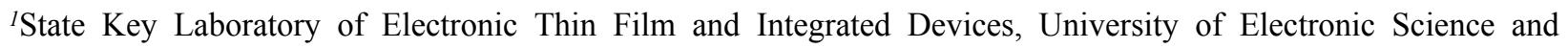
Technology of China, Chengdu 610054, China

${ }^{2}$ State Key Laboratory of Marine Resource Utilization in South China Sea, Hainan University, Haikou 570228, China

${ }^{3}$ School of Material Science and Engineering, Tsinghua University, Beijing 100084, China

${ }^{4}$ School of Chemistry and Chemical Engineering, Guangzhou University, Guangzhou, 510006 China

${ }^{5}$ School of Materials Science and Engineering, North University of China, Taiyuan 030051, China

${ }^{6}$ Key Laboratory of Materials Processing and Mold (Zhengzhou University), Ministry of Education, National Engineering Research Center for Advanced Polymer Processing Technology, Zhengzhou University, Zhengzhou, China

${ }^{7}$ Integrated Composites Lab (ICL), Department of Chemical \& Biomolecular Engineering, University of Tennessee, Knoxville, TN 37934 USA

tThese authors contributed equally to this work

*Corresponding authors: zguo10@utk.edu (Z. G.), linjing@gzhu.edu.cn (J. L.); wangjsh@bjut.edu.cn (J. W.) wangn02@foxmail.com (N.W.). 


\section{Experimental Section}

Chemicals: Lead (II) iodide (99.9985\%) was purchased from Alfa Asear, and Spiro-OMeTAD (>99.7\%) was purchased from Lumtec (Taiwan). All other materials were purchased from SigmaAldrich. All the chemicals were used as received without any treatment.

Methyl ammonium iodide $\left(\mathrm{CH}_{3} \mathbf{N H}_{3} \mathrm{I}\right)$ synthesis: $\mathrm{CH}_{3} \mathrm{NH}_{3} \mathrm{I}$ was synthesized through the reaction of $24 \mathrm{~mL}$ methylamine and $10 \mathrm{~mL}$ hydroiodic acid in a $100 \mathrm{~mL}$ round bottomed flask at $0{ }^{\circ} \mathrm{C}$. Then the solvent was removed by a rotary evaporator at $60^{\circ} \mathrm{C}$. This crude product was re-dissolved into $10 \mathrm{~mL}$ ethanol, than $100 \mathrm{~mL}$ diethyl ether was slowly dropped along the bottle wall, and snowwhite product was deposited. This recrystallization was repeated for three times, and the obtained precipitation was dried in a vacuum oven g at $50{ }^{\circ} \mathrm{C}$ for $24 \mathrm{~h}$.

Synthesis of NSGQDs and GQDs: NSGQDs were synthesized via an effective one-step hydrothermal reaction, and further purified by a dialysis process. The detailed preparation process of NSGQDs has been described in our previous work. ${ }^{63}$ For comparison, GQDs were also synthesized based on the same experimental conditions, except that $0.84 \mathrm{~g}$ citric acid and $0.48 \mathrm{~g}$ $\mathrm{NaOH}$ were used as precursors.

Device fabrication: The PSCs were manufactured on fluorine-doped tin oxide (FTO) glasses. First, FTO substrates were washed via sequential sonication in distilled water, ethanol, acetone, as well as isopropanol for at least $25 \mathrm{~min}$. Then, the cleaned FTO glasses were treated by UV/ozone for 20 min. $220 \mathrm{mg} \mathrm{Fe}\left(\mathrm{NO}_{3}\right)_{3} \cdot 9 \mathrm{H}_{2} \mathrm{O}$ dissolved in $4 \mathrm{~mL}$ ethanol, followed was spin-coated on FTO substrates at $5000 \mathrm{rpm}$ for $30 \mathrm{~s}$. Thereafter, the films were sintered at $450^{\circ} \mathrm{C}$ for $1 \mathrm{~h}$ in an ambient air atmosphere. The obtained films were then spun with $0.5 \mathrm{mg} / \mathrm{mL}$ NSGQDs solution, followed annealed at $120{ }^{\circ} \mathrm{C}$ for $15 \mathrm{~min}$. Prior to making the $\mathrm{CH}_{3} \mathrm{NH}_{3} \mathrm{PbI}_{3}$ precursor solution, $0.02 \mathrm{mg}$ of GQDs as well as NSGQDs were dispersed in $1 \mathrm{ml}$ anhydrous $N$, $N$-dimethylformamide (DMF) by 
$1 \mathrm{~h}$ sonication. Subsequently, methylamine iodide $(0.216 \mathrm{~g})$ and lead iodide $(0.624 \mathrm{~g})$ are dissolved in $1.2 \mathrm{~mL}$ anhydrous DMF, then by stirring for $1 \mathrm{~h}$ to obtain a perovskite/NSGQDs (or GQDs) mixing precursor solution. In order to prepare the control perovskite film, NSGQDs (or GQDs) was not added and other steps remained the same. $80 \mu \mathrm{L}$ perovskite precursor solution was spincoated on $\alpha-\mathrm{Fe}_{2} \mathrm{O}_{3}$ at $5500 \mathrm{rpm}$ for $35 \mathrm{~s}$. Then the sample was quickly washed with $180 \mu \mathrm{L}$ anhydrous chlorobenzene. The samples were immediately annealed at $105^{\circ} \mathrm{C}$ for $10 \mathrm{~min}$. For the NSGQDs modification, $100 \mu \mathrm{L}$ of a stock solution consisting of $5 \mathrm{mg} / \mathrm{mL}$ NSGQDs in chlorobenzene were dropped onto the perovskite film, followed by spinning coating at $5000 \mathrm{rpm}$ for $45 \mathrm{~s}$. Then above films were transferred to a hot plate as well as covered via a glass petri dish. To obtain cross-linked NSGQDs, 8-12 $\mu \mathrm{L}$ of (3-mercaptopropyl) trimethoxysilane was introduced into the petri dish in the process of annealed $\left(105^{\circ} \mathrm{C}\right.$ for $\left.1 \mathrm{~h}\right)$. Next, the hole transport material (HTM) was grown on perovskite film via spin coating with $5000 \mathrm{rpm}$ for $20 \mathrm{~s}$. Finally, electrode of $\sim 100 \mathrm{~nm}$ thick gold was thermally evaporated on the top of the cell.

Device Characterization: XRD characterization were gained by using a Bruker D8 X-ray diffractometer (Bruker D8 Advance diffractometer, Germany). SEM images were characterized through a FE-SEM ((JEM-4800F). The photoelectron characterization was obtained on a photoelectron spectrometer (AC-2, Riken Keiki). PL and TRPL were characterized by using a FP650 (JASCO Corporation). The current -voltage ( $J-V)$ curves were obtained using a digital source meter (2400, Keithley Instruments, USA) and the cell was illuminated by a solar simulator (91192, Oriel, USA) under AM 1.5 G illumination $\left(100 \mathrm{~mW} \mathrm{~cm}^{-2}\right)$. IPCE were measured on a QEX10 solar cell quantum efficiency measurement system (Newport). 

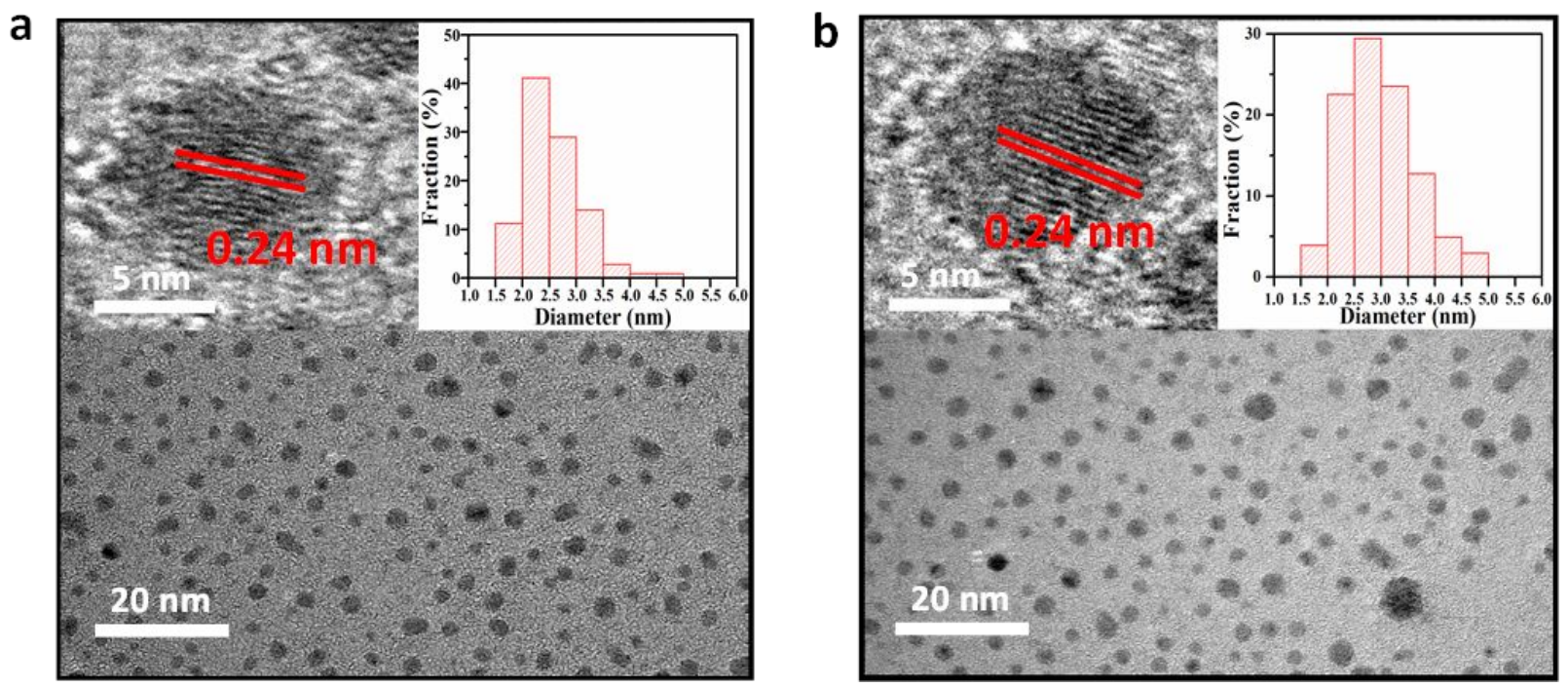

Figure S1. TEM image of (a) NSGQDs and (b) GQDs. 

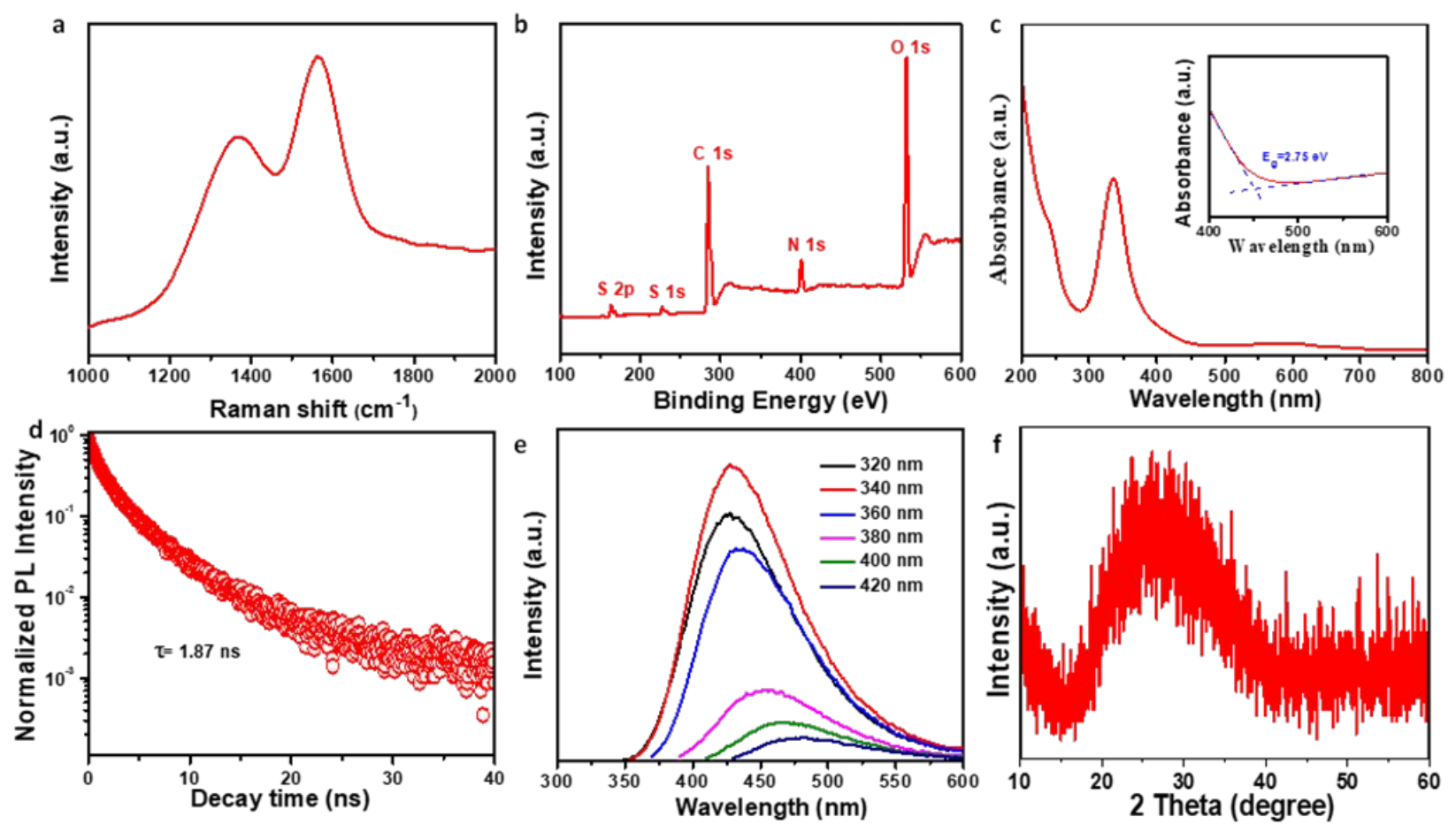

Figure S2. (a) Raman spectrum, (b) XPS spectrum, (c) UV-Vis spectrum, (d) PL decay spectrum, (e) PL spectrum in different excitation wavelengths and (f) XRD of NSGQDs samples.
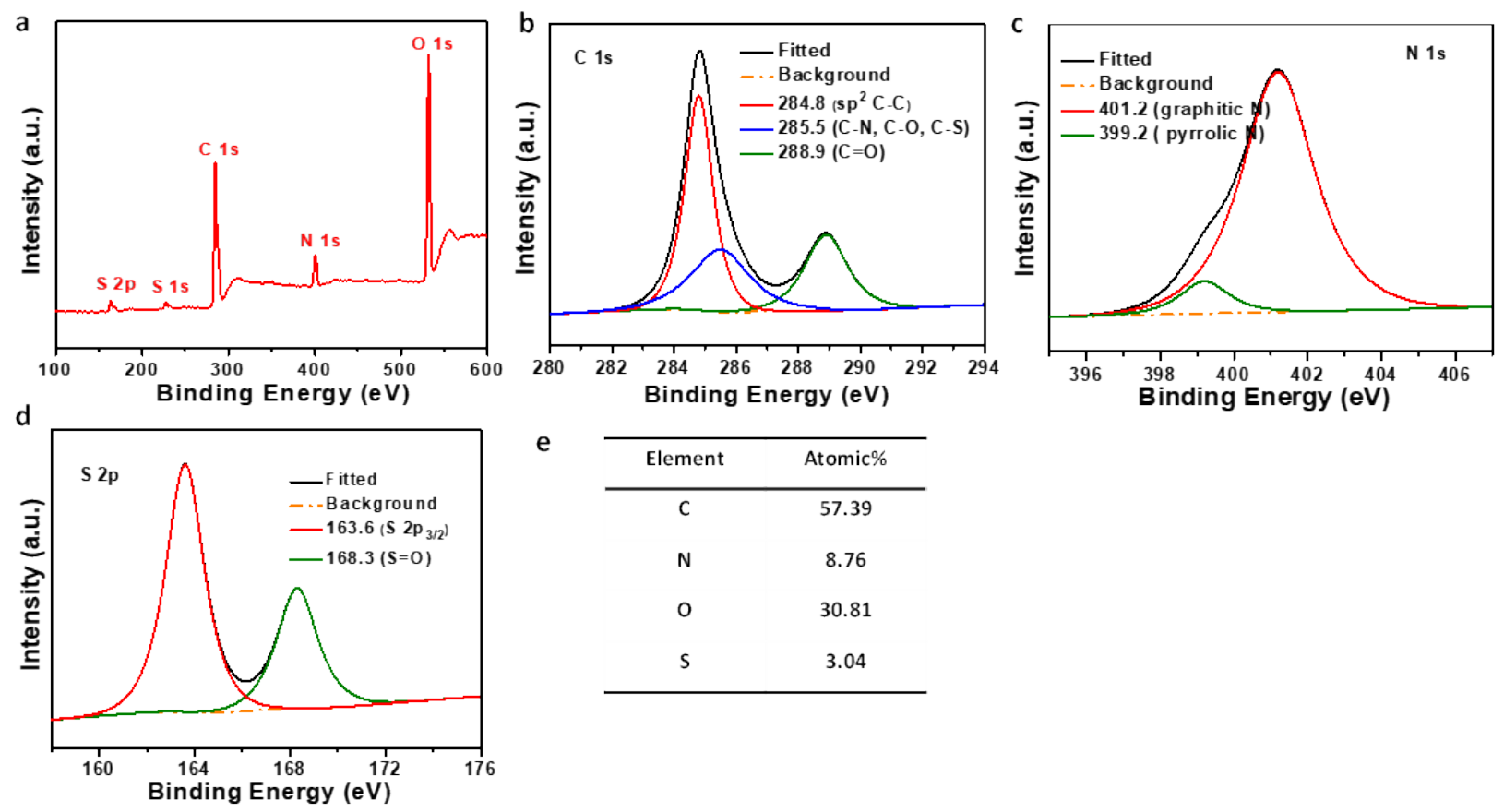

e

\begin{tabular}{cc}
\hline Element & Atomic\% \\
\hline $\mathrm{C}$ & 57.39 \\
$\mathrm{~N}$ & 8.76 \\
$\mathrm{O}$ & 30.81 \\
$\mathrm{~S}$ & 3.04 \\
\hline
\end{tabular}

Figure S3. High-resolution XPS of C 1s (a), O 1s (b), N 1s (c), and S 2p (d) spectra of NSGQDs. (e) XPS compositional analysis of NSGQDs. 
a

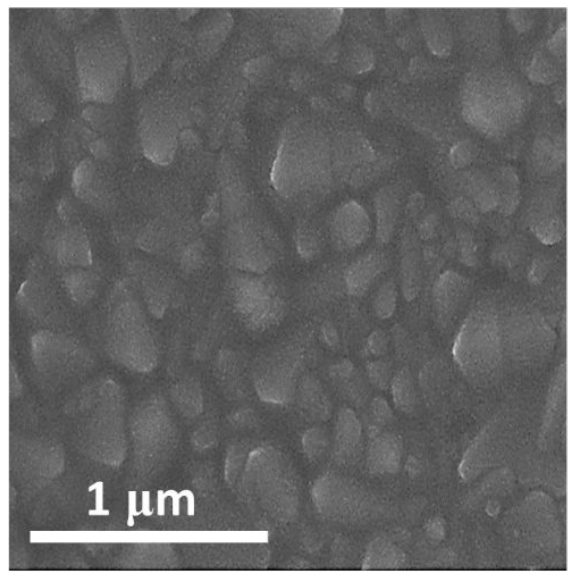

b

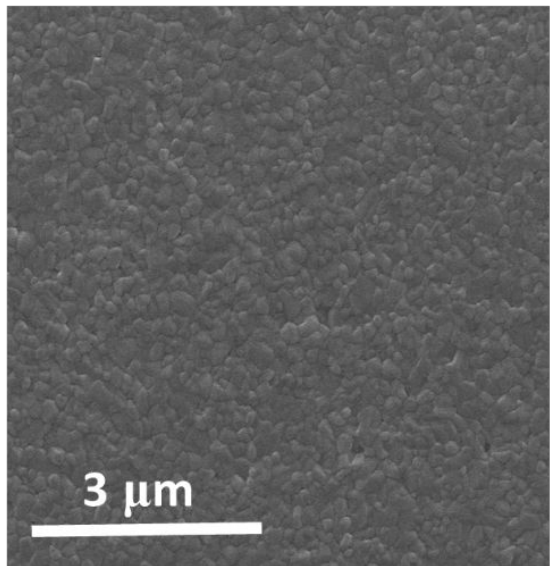

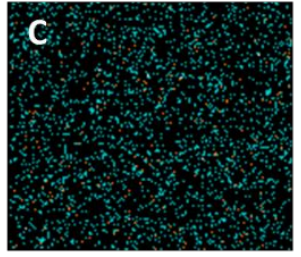
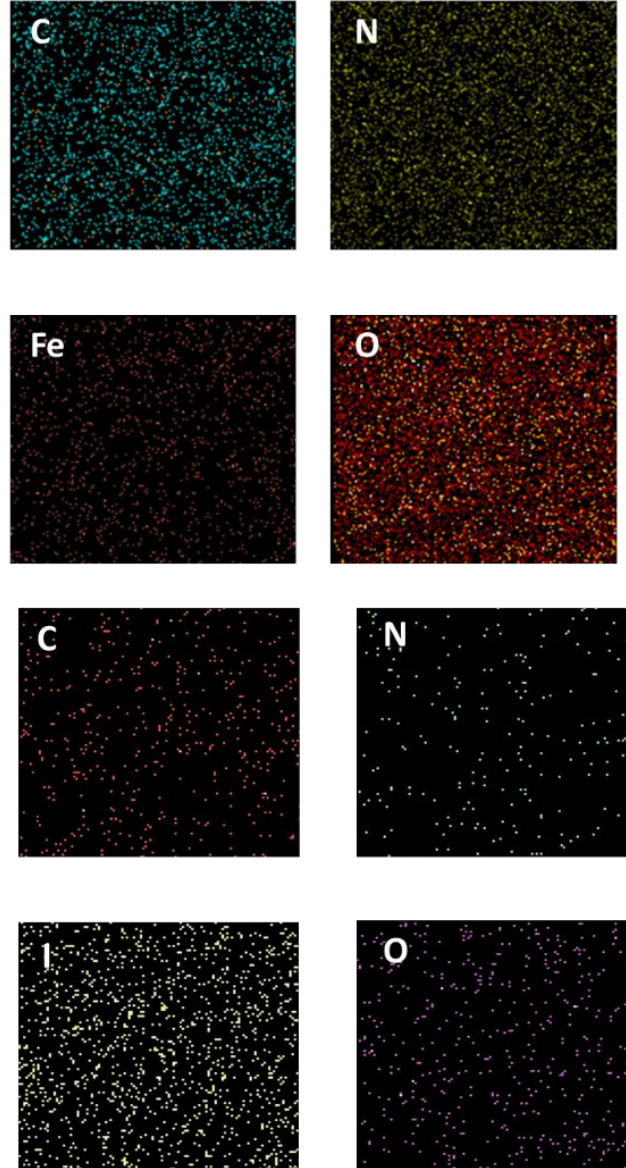
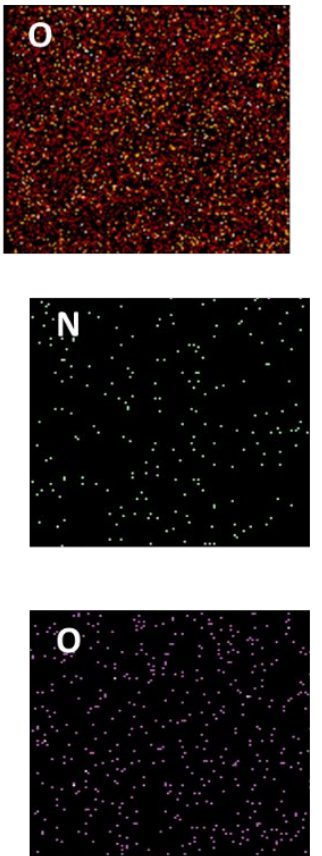

S
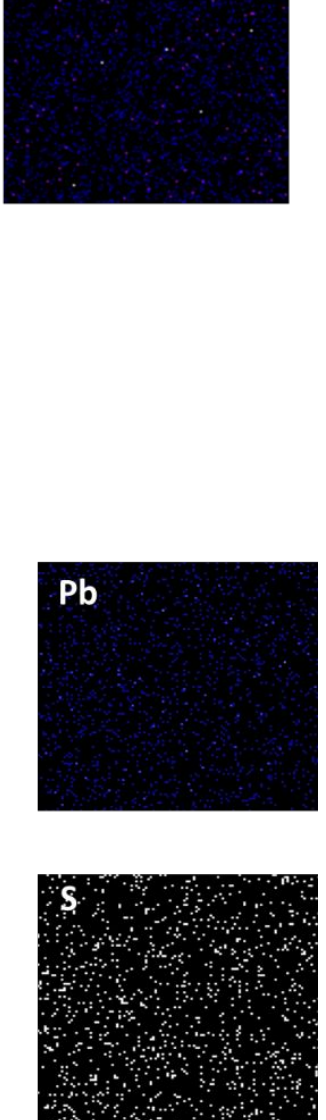

Figure S4. (a) EDS elemental mapping images of a $\alpha-\mathrm{Fe}_{2} \mathrm{O}_{3}$ film covered with an ultrathin NSGQD layer. Top left: SEM image. (b) EDS mapping images of a pristine perovskite film covered with NSGQDs. Lower left: SEM image.
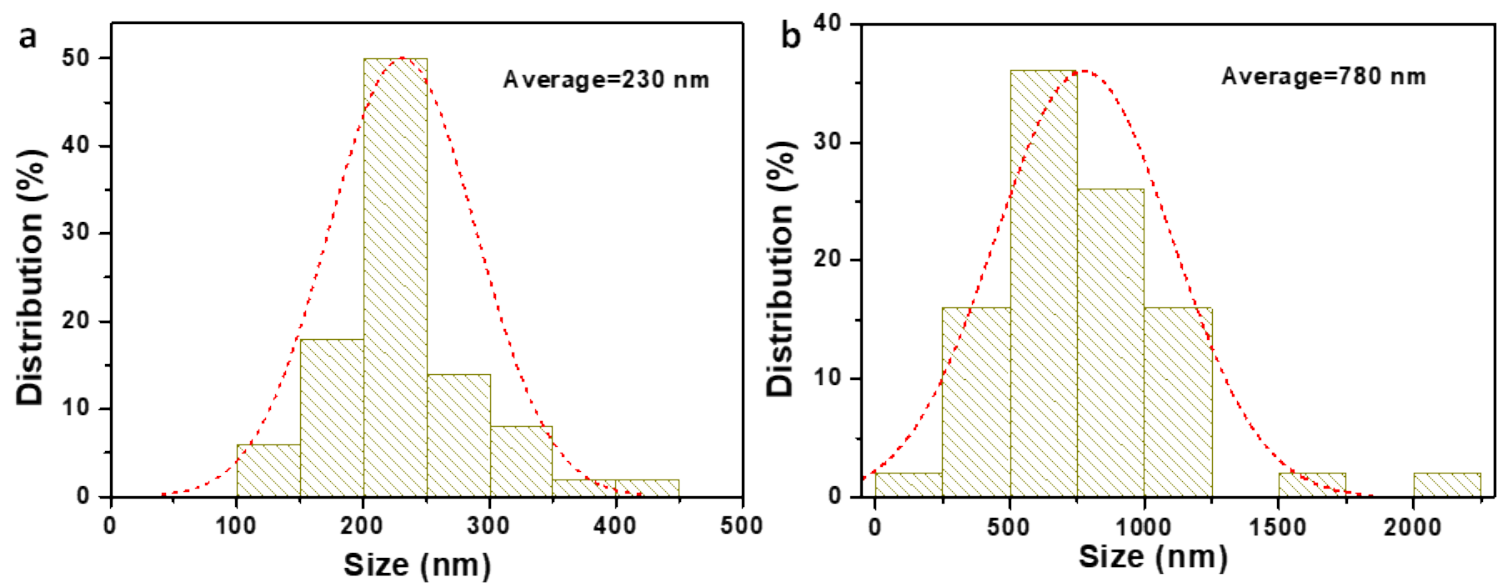

Figure S5. The grain size distributions of the (a) pristine perovskite and (b) the perovskite+NSGQDs. 

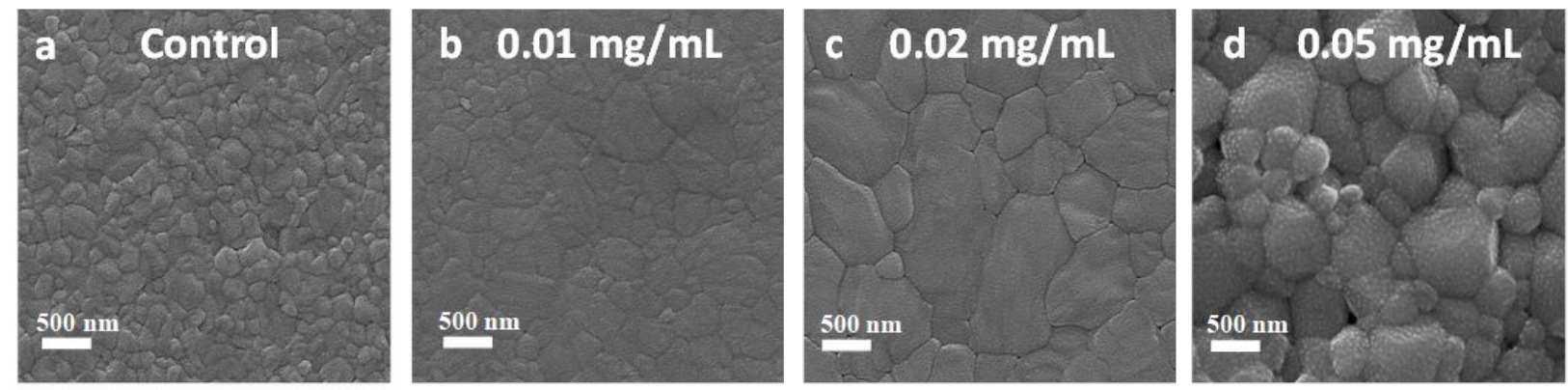

Figure S6. Top-view SEM image of (a) pristine perovskite, (b) perovskite $+0.01 \mathrm{mg} / \mathrm{mL}$ NSGQDs,

(c) perovskite $+0.02 \mathrm{mg} / \mathrm{mL}$ NSGQDs, and (d) perovskite+0.05 mg/mL NSGQDs.
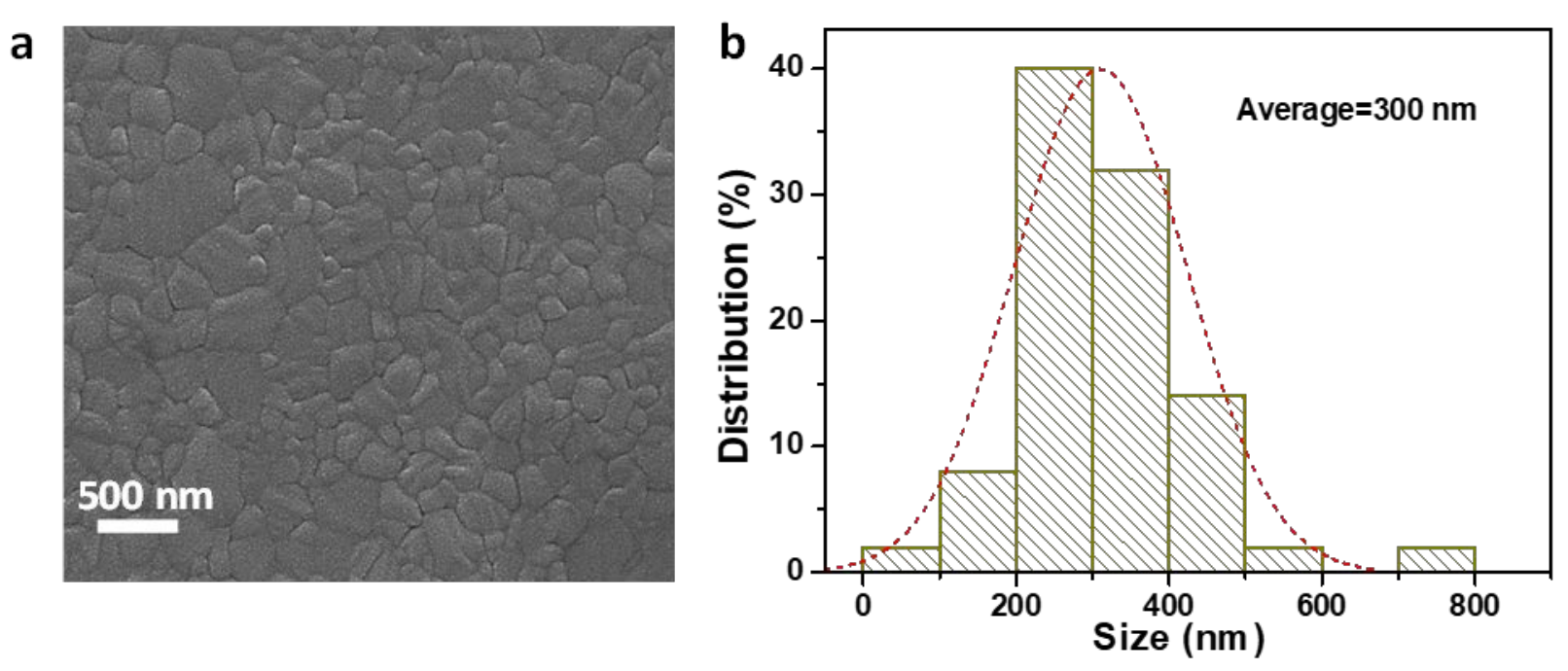

Figure S7. (a) SEM top-view image of the perovskite+GQDs film. (b) The grain size distributions of the perovskite+GQDs film. 


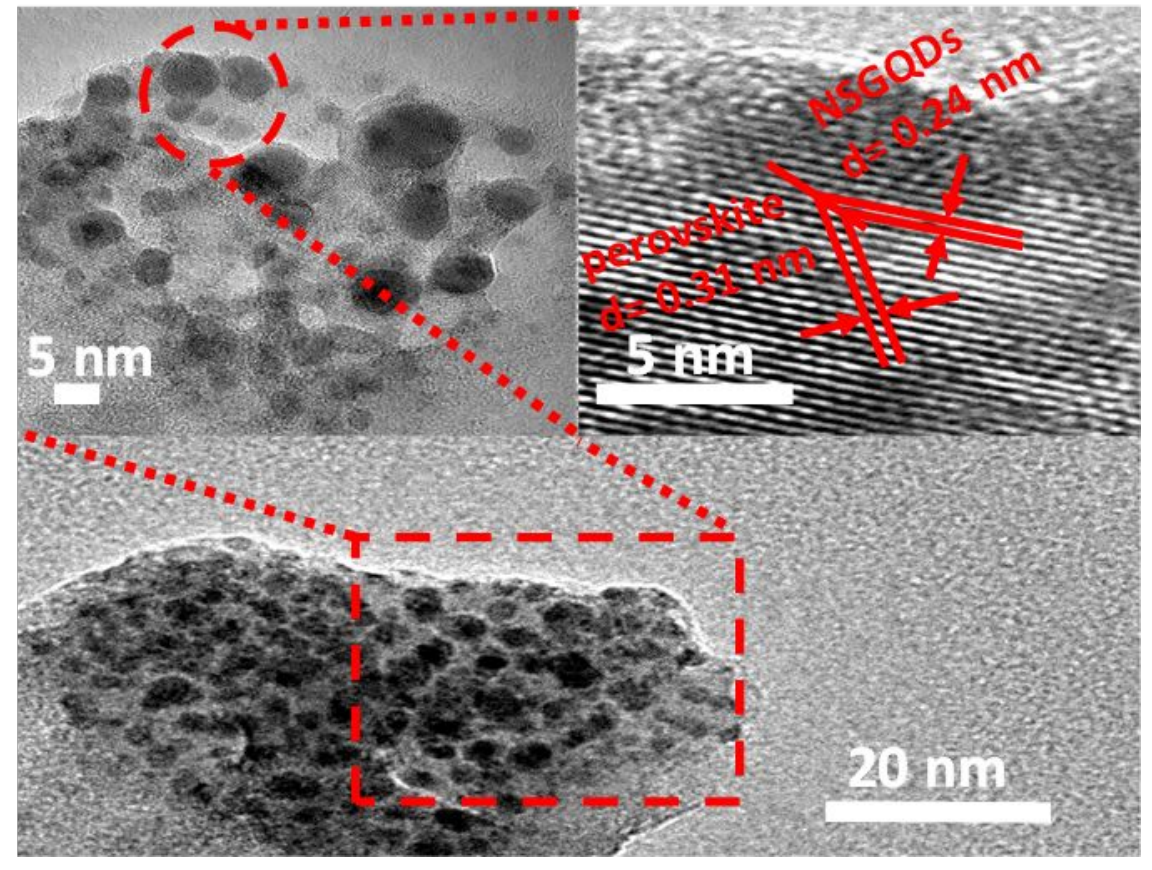

Figure S8. TEM images of the perovskite+NSGQDs with an increasing resolution.

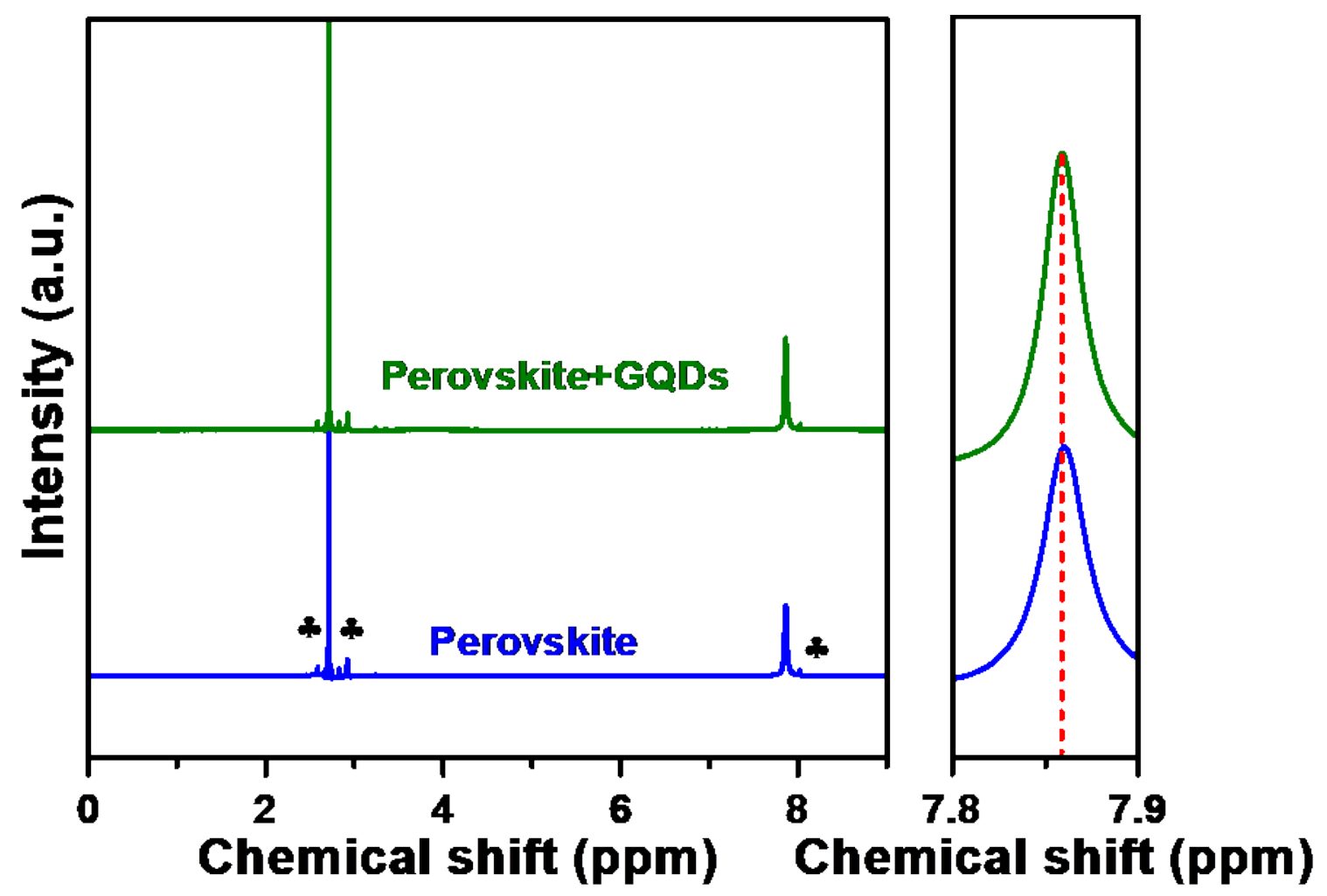

Figure S9. ${ }^{1} \mathrm{H}-\mathrm{NMR}$ of the perovskite and perovskite+GQDs solutions collected in DMF- $\mathrm{d}_{7}$ (stars represent the peaks from the DMF- $\mathrm{d}_{7}$ ). 

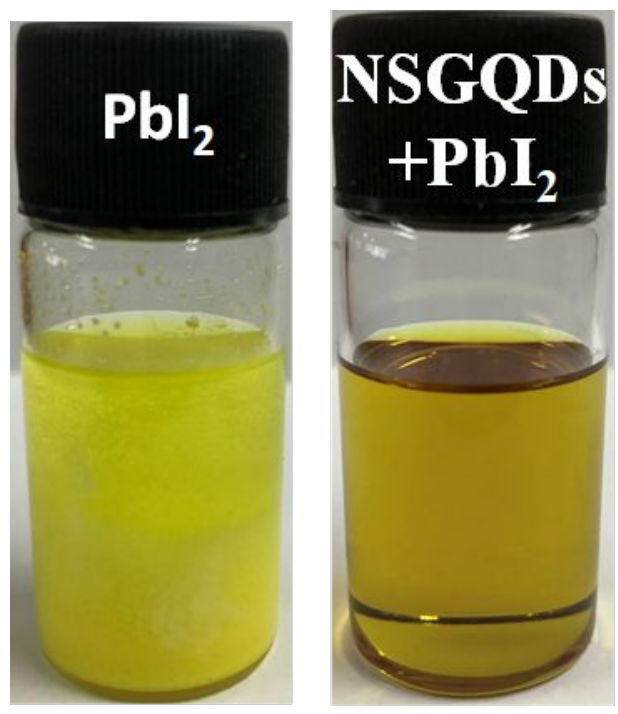

Figure S10. Photograph of $\mathrm{PbI}_{2}$ and NSGQDs $+\mathrm{PbI}_{2}$ solutions. The concentration of $\mathrm{PbI}_{2}$ is 1.35 $M$ in DMF.

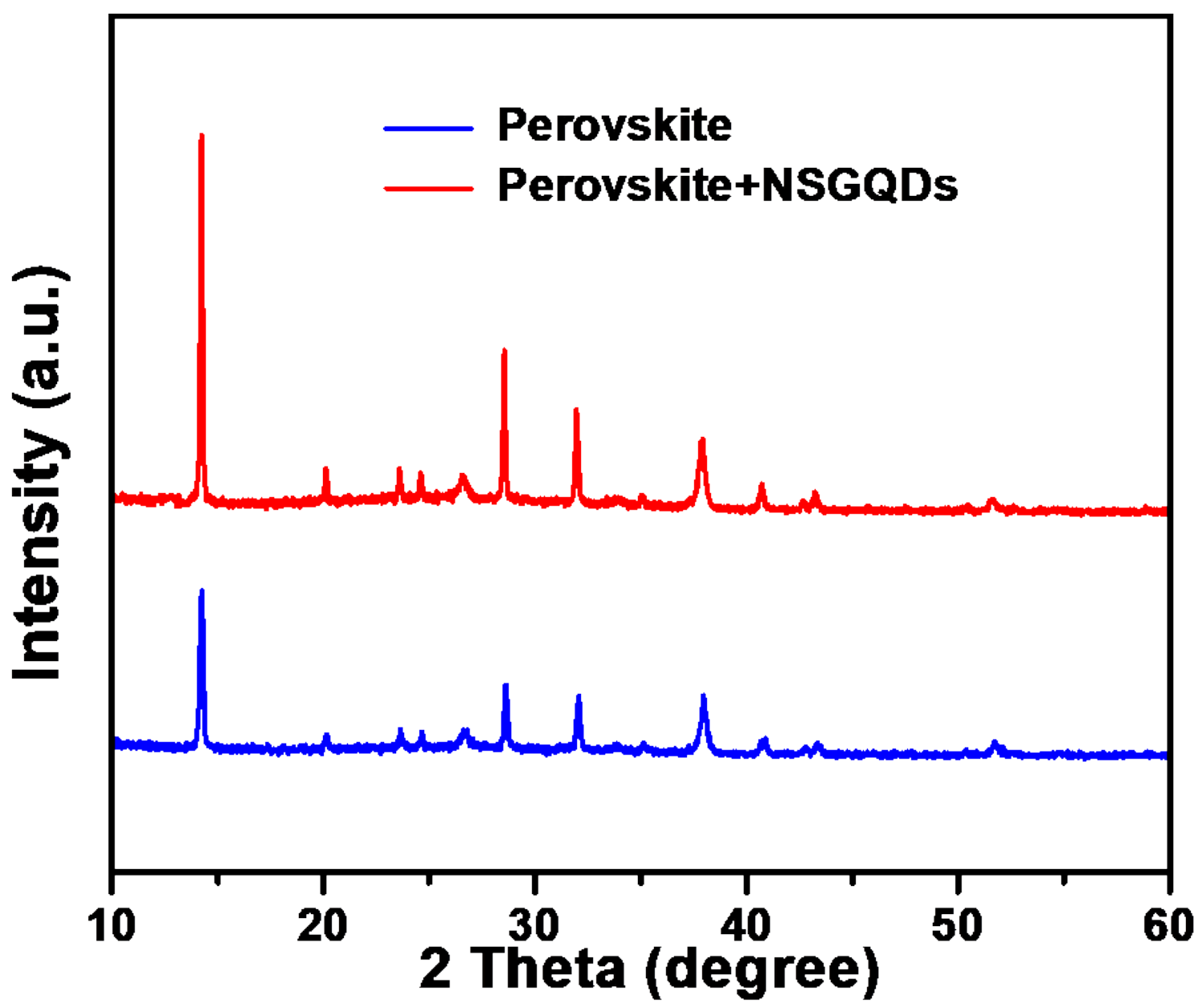

Figure S11. The XRD patterns of different perovskite films. 


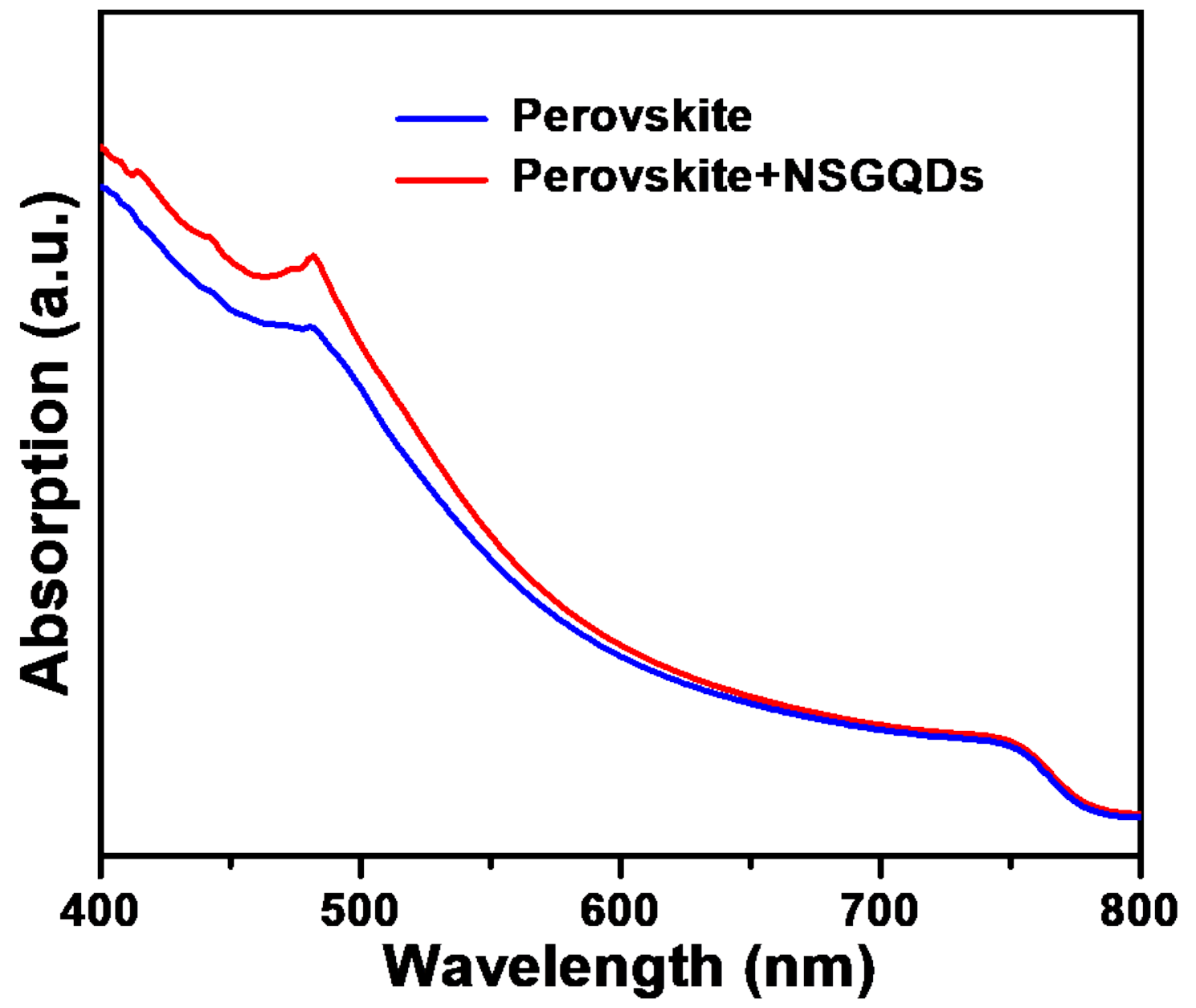

Figure S12. UV-Vis measurement for different perovskite films. 


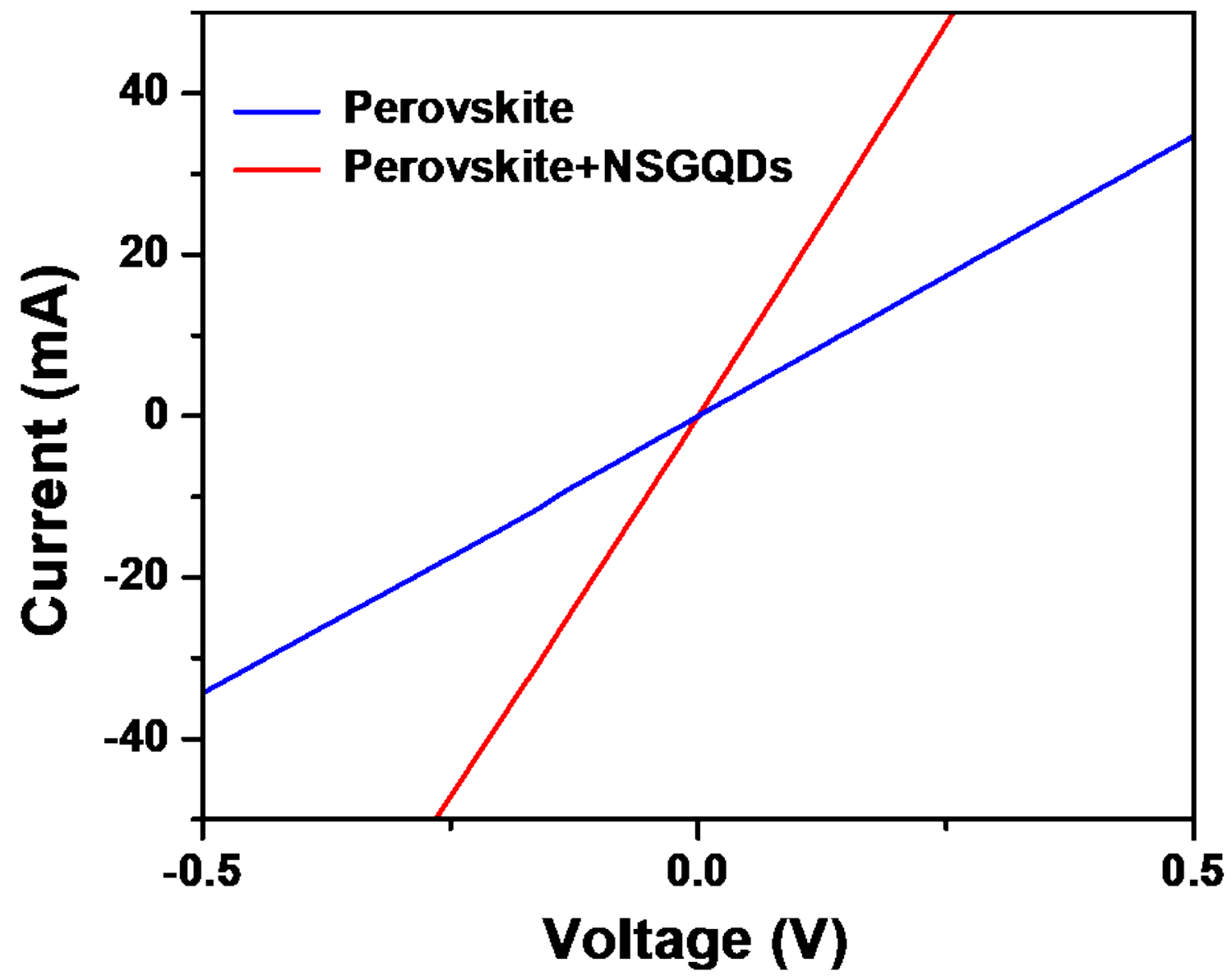

Figure S13. I-V characteristic of the FTO/pristine perovskite and the perovskite+NSGQDs/Au devices. 


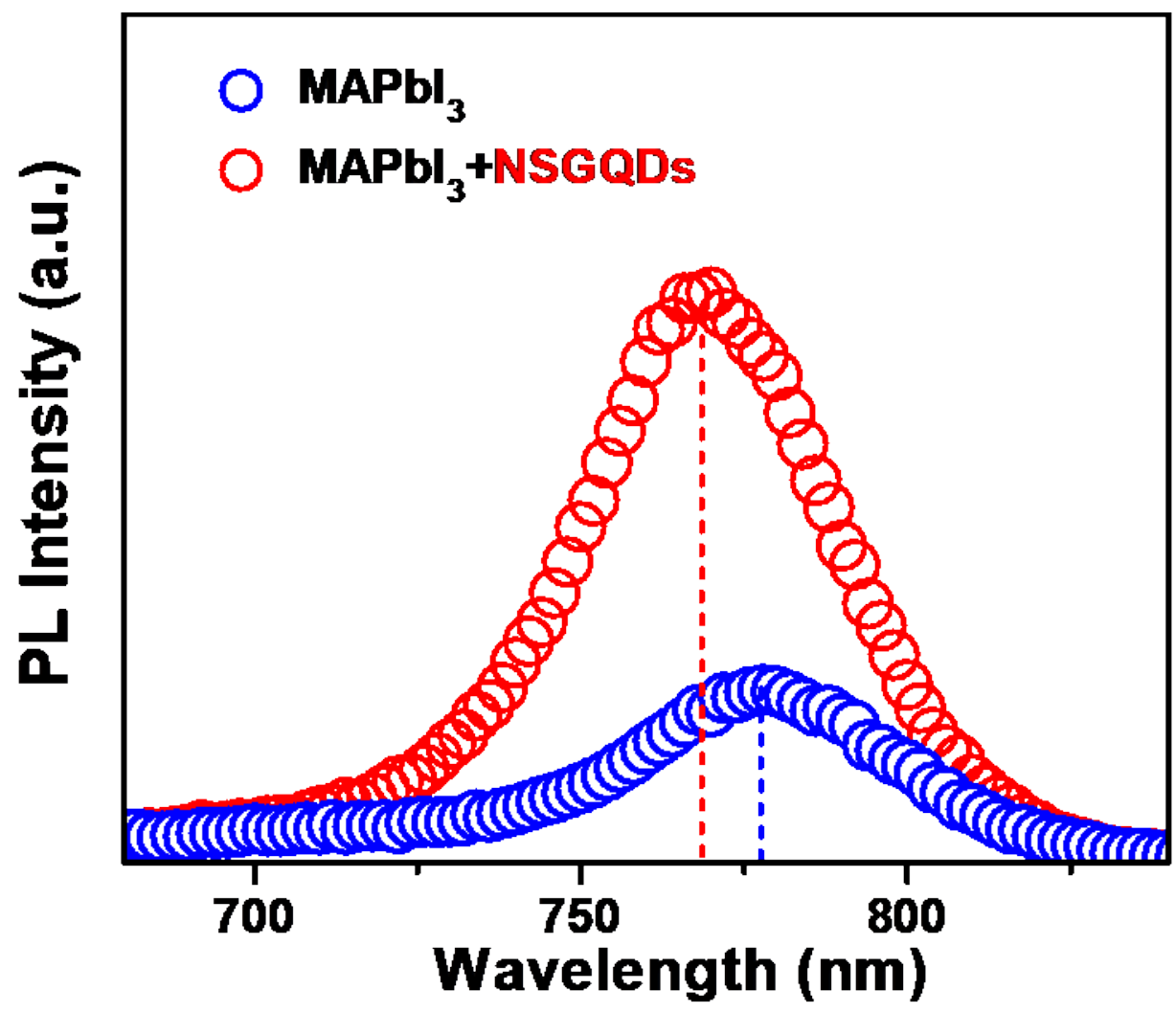

Figure S14. Steady-state PL spectra of different perovskite films with pristine perovskite and perovskite+NSGQDs. 


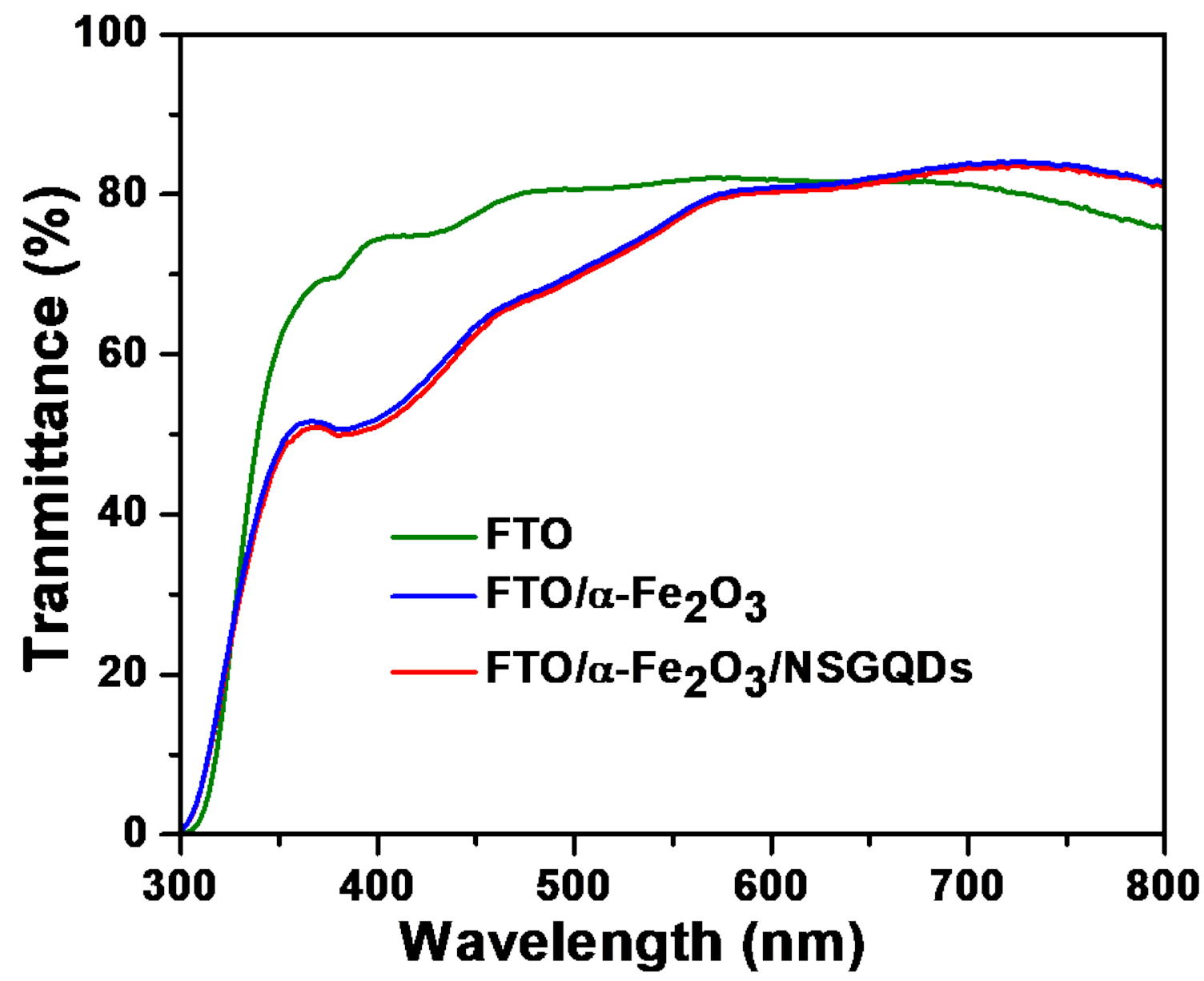

Figure 15. Transmission spectra of $\alpha-\mathrm{Fe}_{2} \mathrm{O}_{3}$ and $\alpha-\mathrm{Fe}_{2} \mathrm{O}_{3} / \mathrm{NSGQDs}$ layers. 

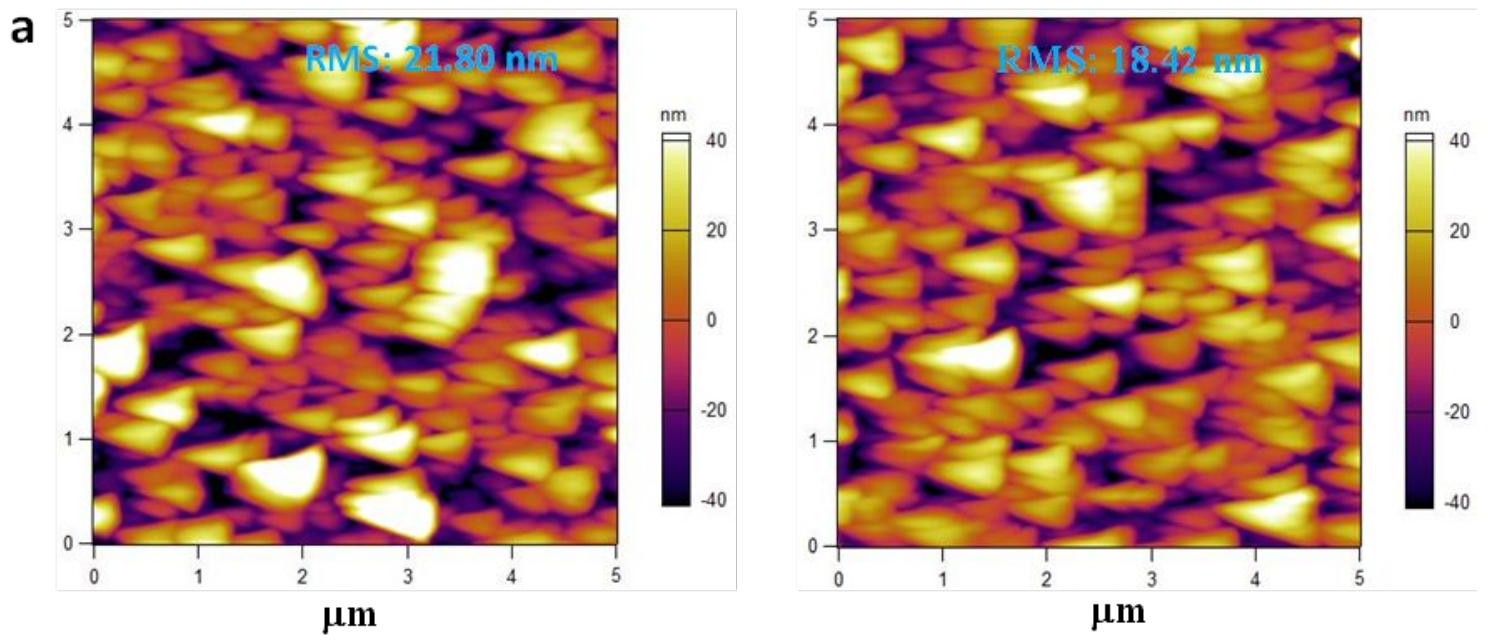

Figure S16. Top view AFM images of (a) $\alpha-\mathrm{Fe}_{2} \mathrm{O}_{3}$ and (b) $\alpha-\mathrm{Fe}_{2} \mathrm{O}_{3} / \mathrm{NSGQDs}$ layers.
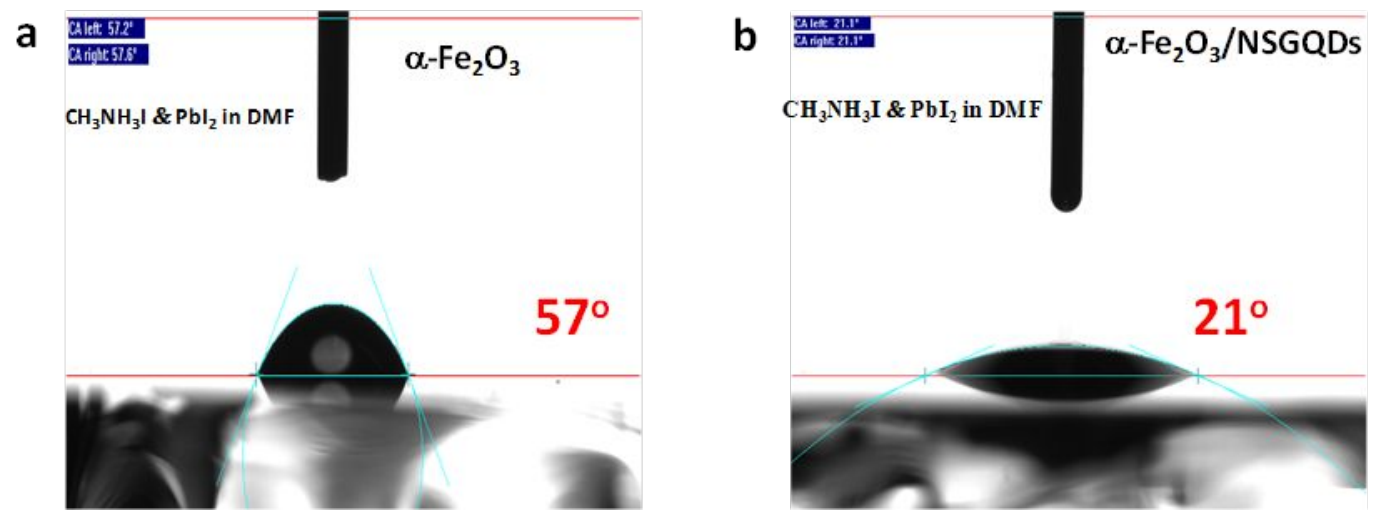

Figure S17. Contact angle (CA) of the perovskite precursor solution on the surface of (a) $\alpha$ $\mathrm{Fe}_{2} \mathrm{O}_{3}$ and (b) $\alpha-\mathrm{Fe}_{2} \mathrm{O}_{3} / \mathrm{NSGQDs}$ layers. 


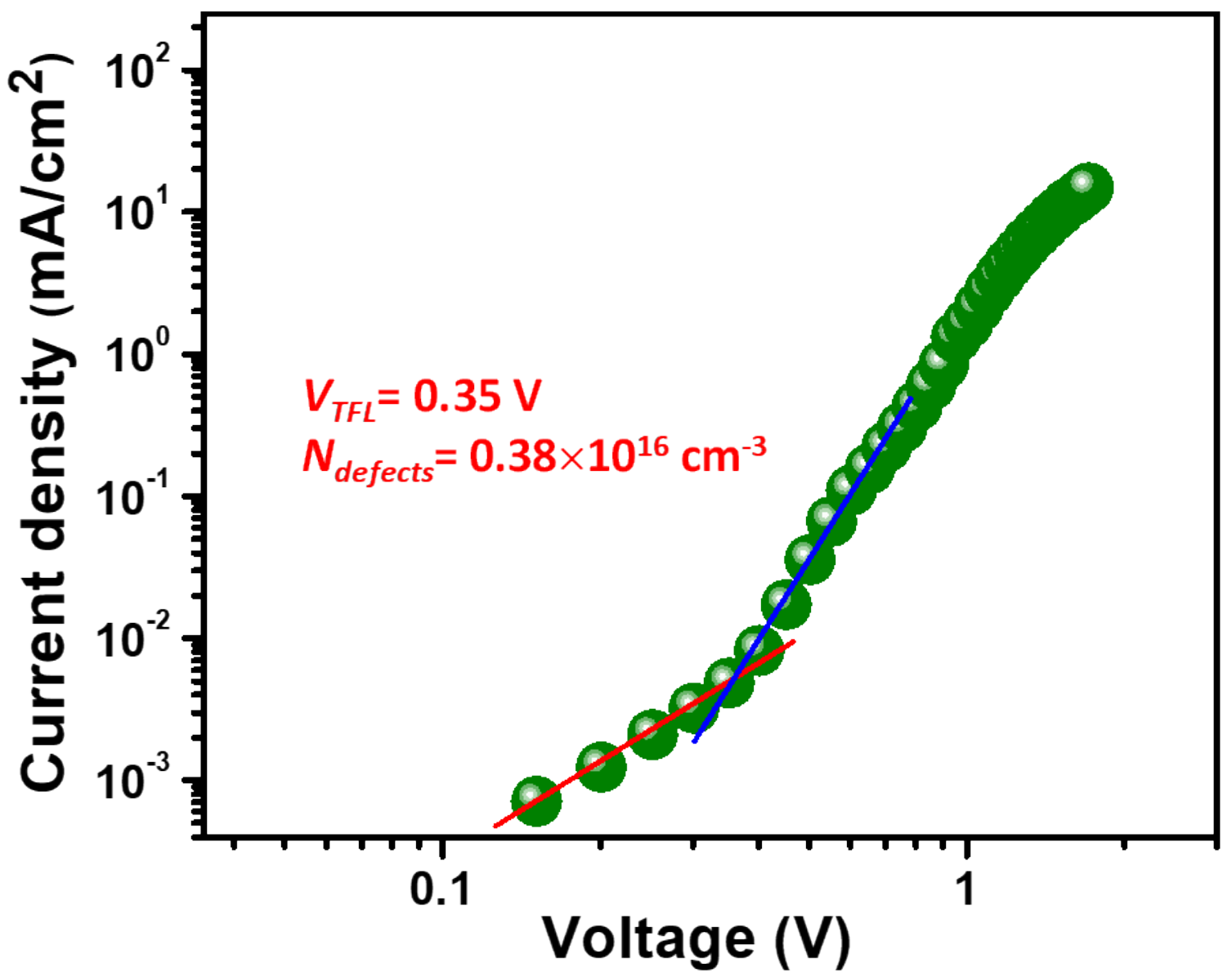

Figure S18. Current density-voltage characteristics of devices with FTO/ $\alpha$ $\mathrm{Fe}_{2} \mathrm{O}_{3} /$ perovskite+NSGQDs/NSGQDs/PCBM/Au(electron-only devices). 


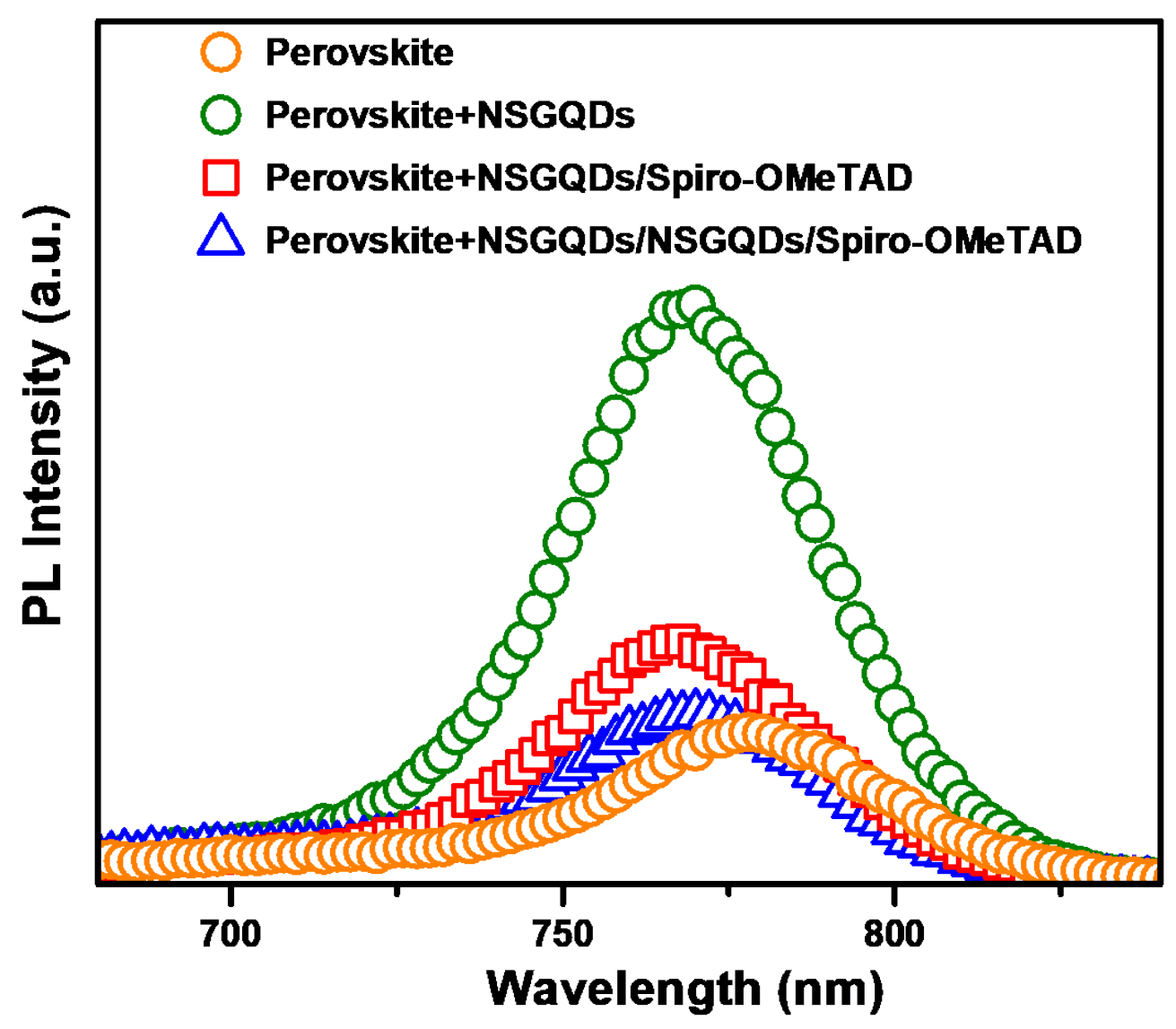

Figure S19. Steady-state PL spectra from different perovskite films. 

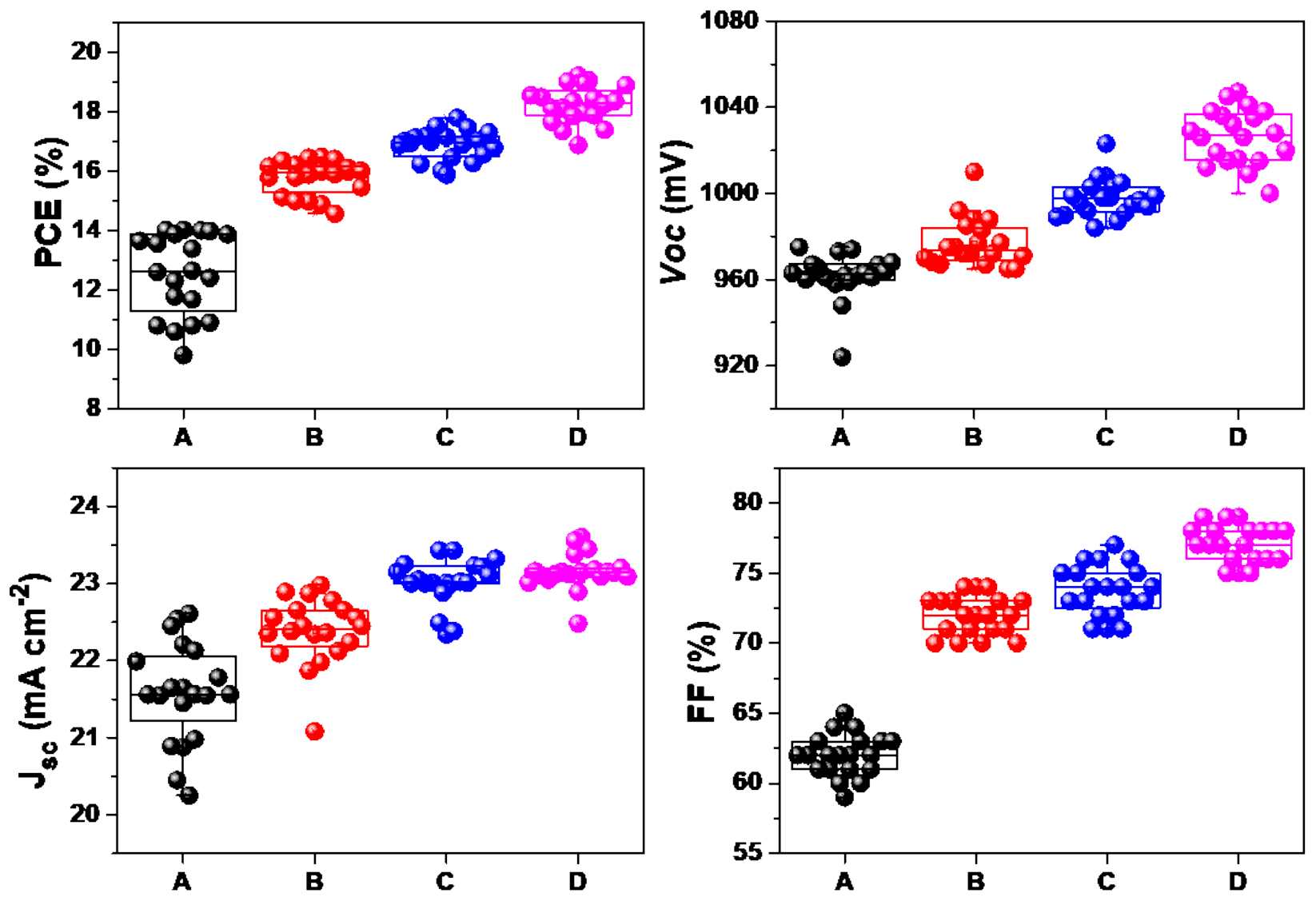

Figure S20. Statistical distribution of the performance for PSCs with different structure: $\alpha$ $\mathrm{Fe}_{2} \mathrm{O}_{3} / \mathrm{MAPbI}_{3}(\mathrm{~A}) ; \alpha-\mathrm{Fe}_{2} \mathrm{O}_{3} / \mathrm{MAPbI}_{3}+\mathrm{NSGQDs}(\mathrm{B}) ; \alpha-\mathrm{Fe}_{2} \mathrm{O}_{3} / \mathrm{NSGQDs} / \mathrm{MAPbI}_{3}+\mathrm{NSGQDs}(\mathrm{C}) ;$ $\alpha-\mathrm{Fe}_{2} \mathrm{O}_{3} / \mathrm{NSGQDs} / \mathrm{MAPbI}_{3}+\mathrm{NSGQDs} / \mathrm{NSGQDs}$ (D). 

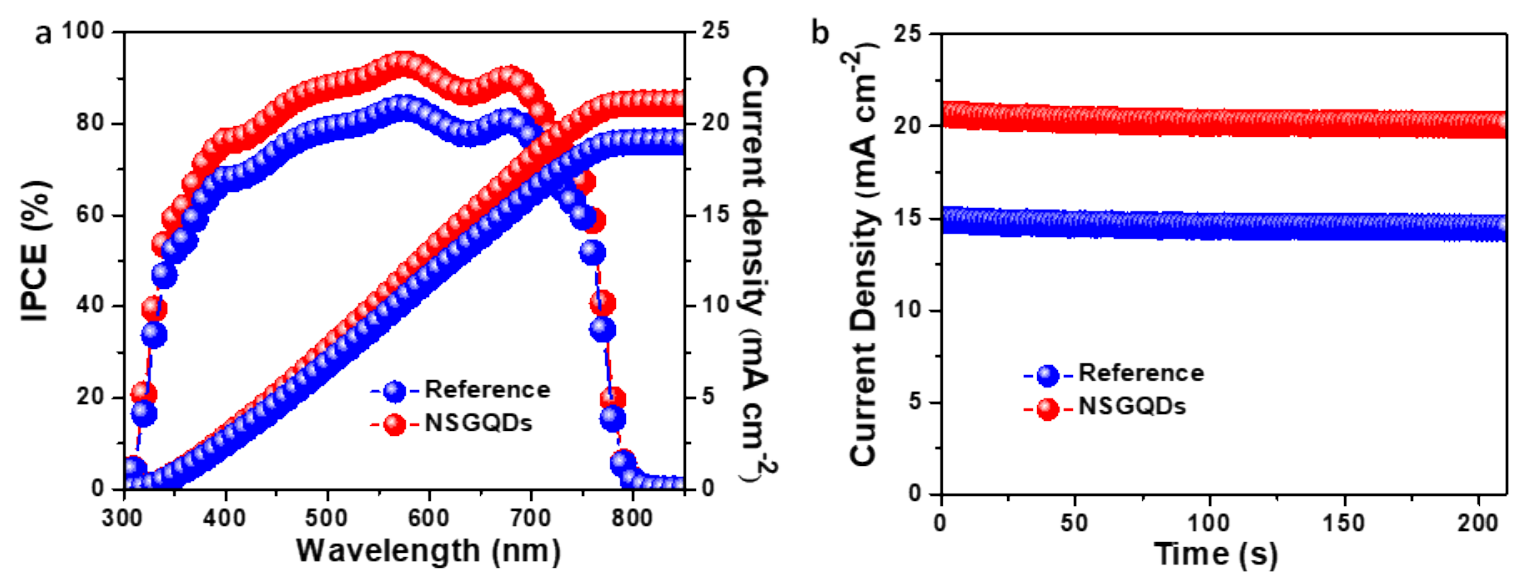

Figure S21. (a) The corresponding IPCE spectrum of different devices. (b) Steady-state current densities of NSGQDs-based and pristine solar cells measured at a bias of $0.90 \mathrm{~V}$ and $0.75 \mathrm{~V}$ under $\mathrm{AM}=1.5 \mathrm{G}$ irradiation, respectively.
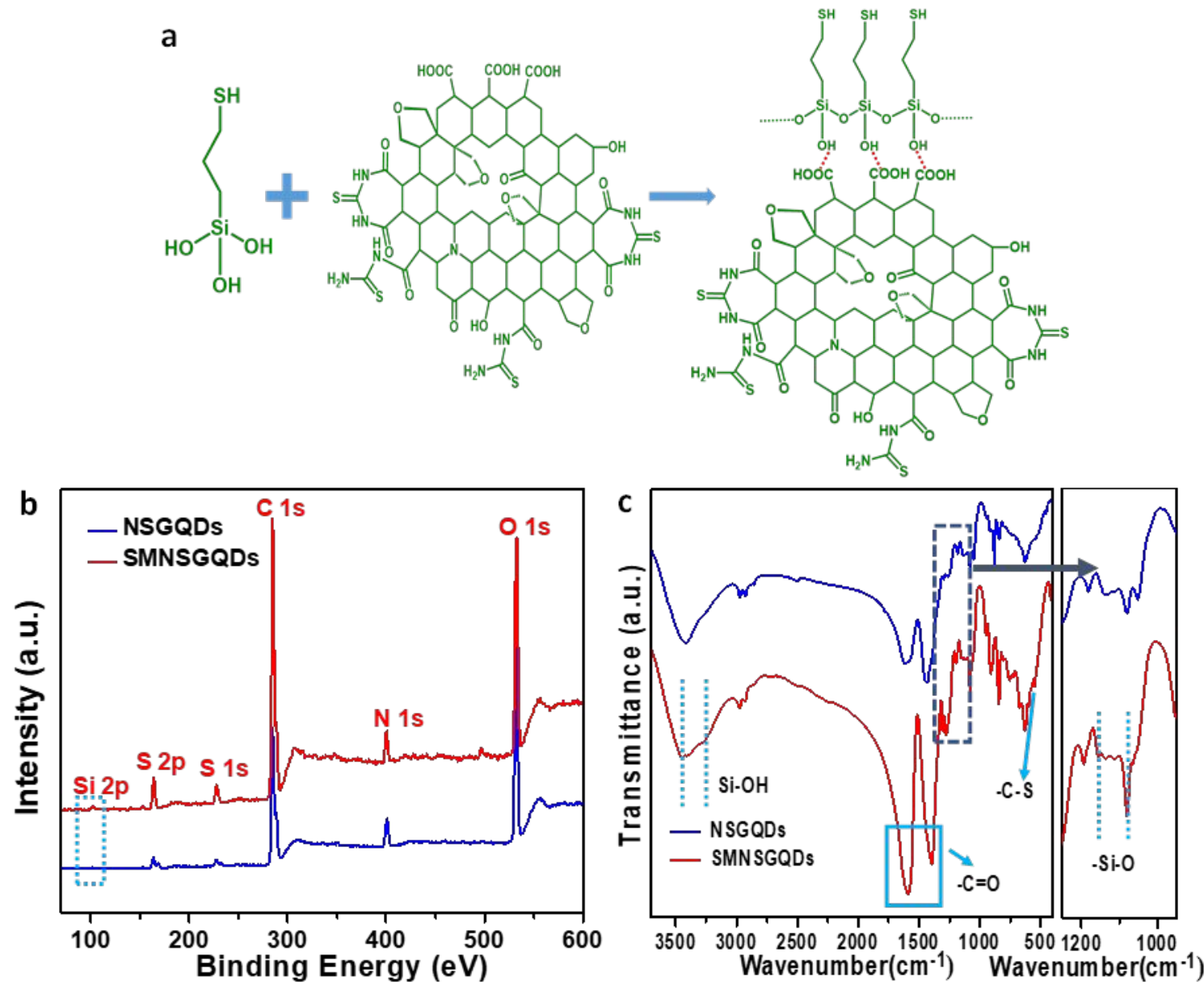

Figure S22. (a) The formation pathway of SMNSGQDs. (b) XPS and (c) FTIR spectra of NSGQDs and SMNSGQDs. 

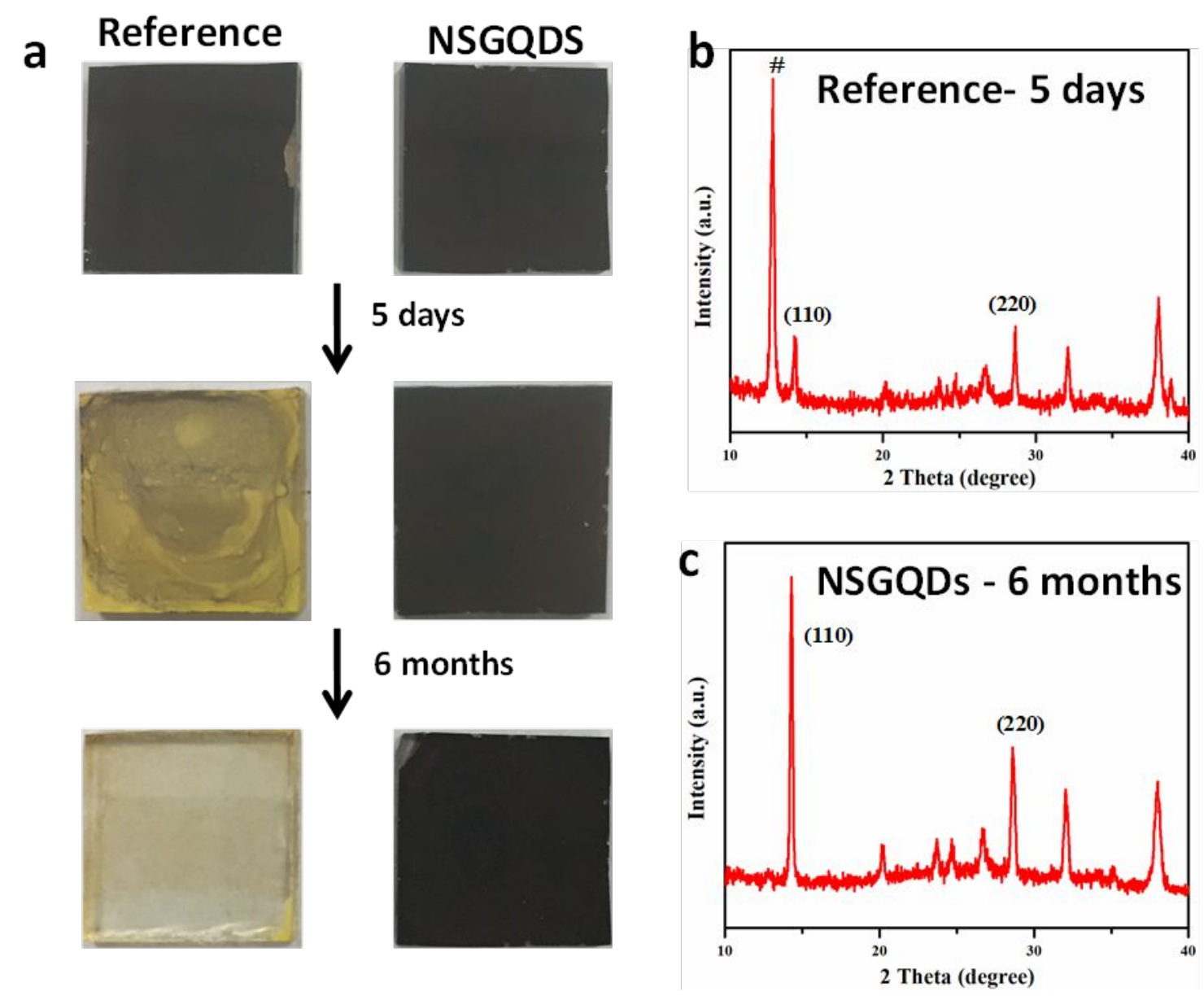

Figure S23. (a) Photographs of pristine perovskite and NSGQDs/perovskite+NSGQDs/SMNSGQDs films after exposure to air with a humidity of $50 \pm$ 10 RH\%. The XRD patterns of (b) a pristine perovskite film and (c) a NSGQDs/perovskite+NSGQDs/SMNSGQDs film after exposure in moist air (50 $\pm 10 \mathrm{RH} \%$ air). The \# symbol highlights the XRD peak corresponding to the (001) plane of $\mathrm{PbI}_{2}$. 


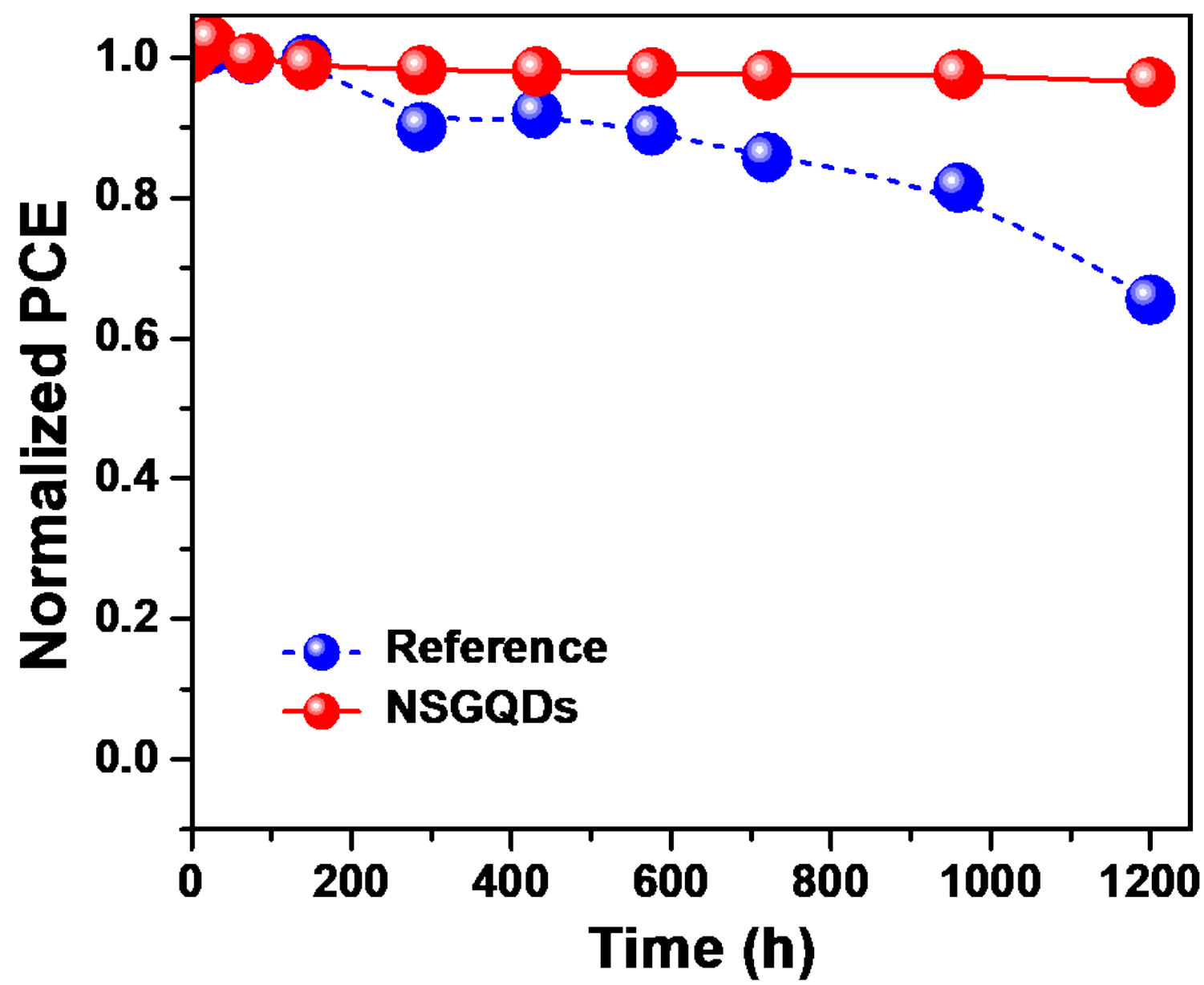

Figure S24. Long-term stability of the perovskite solar cells in a low relative humidity environment $(10 \pm 5 \mathrm{RH} \%)$. 
Table S1. Photovoltaic performance of devices without and with NSGQDs measured under reverse scans for different electron transport layers. The performance parameters were averaged over 10 devices.

\begin{tabular}{|c|c|c|c|c|c|c|}
\hline ETL & PSCs & $V_{\text {oc }}(\mathrm{mV})$ & $J_{\mathrm{sc}}\left(\mathrm{mA} \mathrm{cm}^{-2}\right)$ & FF (\%) & PCE (\%) & $\begin{array}{c}\text { Best PCE } \\
(\%)\end{array}$ \\
\hline \multirow{2}{*}{$\alpha-\mathrm{Fe}_{2} \mathrm{O}_{3}$} & Reference & $962 \pm 38$ & $21.65 \pm 0.97$ & $62 \pm 3$ & $13.3 \pm 0.78$ & 14.0 \\
\hline & NSGQDs & $1026 \pm 21$ & $23.15 \pm 0.45$ & $77 \pm 2$ & $18.6 \pm 0.43$ & 19.2 \\
\hline \multirow{2}{*}{$\mathrm{TiO}_{2}$} & Reference & $1019 \pm 48$ & $22.48 \pm 0.85$ & $67 \pm 2$ & $15.4 \pm 0.82$ & 16.1 \\
\hline & NSGQDs & $1038 \pm 37$ & $23.15 \pm 0.63$ & $74 \pm 3$ & $17.6 \pm 0.56$ & 18.5 \\
\hline \multirow{2}{*}{$\mathrm{SnO}_{2}$} & Reference & $1028 \pm 56$ & $22.68 \pm 0.72$ & $71 \pm 4$ & $16.5 \pm 0.45$ & 17.1 \\
\hline & NSGQDs & $1041 \pm 34$ & $23.18 \pm 0.48$ & $75 \pm 3$ & $18.4 \pm 0.68$ & 19.1 \\
\hline
\end{tabular}

\section{References}

(1) Liu, T.; Yu, K.; Gao, L.; Chen, H.; Wang, N.; Hao, L.; Li, T.; He, H.; Guo, Z. A graphene quantum dot decorated SrRuO3 mesoporous film as an efficient counter electrode for highperformance dyesensitized solar cells. J. Mater. Chem. A 2017, 5, 17848. 